\title{
O Estudo de Impacto de Vizinhança como ferramenta de Gestão Urbana em Municípios Paulistas de Médio Porte (100 mil a $\mathbf{4 0 0}$ mil habitantes)
}

\author{
The Neighborhood Impact Study as an Urban Management \\ tool in the São Paulo Municipalities of Medium Size (100 \\ thousand to 400 thousand inhabitants)
}

Felipe Facci Inguaggiato [a] [D, Fábio Noel Stanganini [a] [D]

Edson Augusto Melanda [a] [D]

[a] Universidade Federal de São Carlos (UFSCar), Departamento de Engenharia Civil, Programa de Pós-Graduação em Engenharia Urbana, São Carlos, SP, Brasil

Como citar: Inguaggiato, F. F., Stanganini, F. N., \& Melanda, E. A. (2021). O Estudo de Impacto de Vizinhança como ferramenta de Gestão Urbana em Municípios Paulistas de Médio Porte (100 mil a 400 mil habitantes). urbe. Revista Brasileira de Gestão Urbana, v. 13, e20200059. https://doi.org/10.1590/2175-3369.013.e20200059

\section{Resumo}

No ano de 2001, o Estatuto das Cidades deu obrigatoriedade à elaboração de Planos Diretores (PD) a municípios com população acima de 20.000 habitantes, entre outros critérios. No mesmo Estatuto, existe um importante instrumento para a gestão sustentável das cidades: 0 Estudo de Impacto de Vizinhança (EIV), que busca atenuar impactos negativos de empreendimentos no espaço urbano. O Estado de São Paulo possui 645 municípios, e um quarto da população total reside em municípios de médio porte aqueles entre 100.000 e 400.000 habitantes, sendo, portanto, obrigatória nesses municípios a elaboração de PD, assim como o EIV como instrumento legislativo. 0 objetivo deste artigo é levantar a legislação sobre EIV nos municípios preestabelecidos, através de revisão bibliográfica e legislativa referente ao tema. A partir desse levantamento, notou-se que 28,4\% dos municípios não possuem, ou apenas fazem menção ao EIV em seus documentos. Outros 11,6\% possuem cópia do que é exigido nos Artigos 36 a 38 da Lei 10.257/2001, referentes ao EIV, e 60\% possuem legislação complementar ao proposto pela Lei. Logo, observam-se casos de municípios que aportam o EIV de forma satisfatória, e outros que não apresentam condições legislativas para auxiliar ou mitigar impactos da instalação de empreendimentos.

Palavras-chave: Estudo de Impacto de Vizinhança. EIV. Urbanização. Legislação. Plano Diretor.

FFI é geógrafo, mestre em engenharia urbana, e-mail: fp.facci@hotmail.com

FNS é geógrafo, doutor em engenharia urbana, e-mail: fnsgeo@gmail.com

EAM, doutor em ciência da computação e matemática computacional, e-mail: melanda@gmail.com 


\section{Abstract}

In 2001, the Statute of Cities mandated the elaboration of Master Plans (PD) to municipalities with a population above 20,000 inhabitants, besides other criteria. Among these DPs, there's an indispensable instrument for sustainable management of cities: The Neighborhood Impact Study (EIV), which seeks to mitigate negative impacts of enterprises in urban space. The State of São Paulo has 645 municipalities, where a quarter of the total population resides in medium-sized municipalities - those between 100,000 and 400,000 inhabitants, giving mandatory character to the development of PD, as well as EIV as a legislative instrument. The purpose of this article is to raise the legislation regarding EIV in the pre-established municipalities through bibliographic and legislative revision related to the theme. Even so, $28.4 \%$ of the municipalities either do not have or only mention in their legislation about the EIV. Another 11.6\% have a copy of what is required in articles 36 to 38 of Law 10.257 / 2001, referring to the EIV, and 60\% have legislation complementary to that proposed by the Law. However, there are cases of municipalities that provide EIV satisfactorily, and others that don't have legislative conditions or to assist or mitigate impacts of the installation of projects.

Keywords: Neighborhood Impact Study. NIS. Urbanization. Lesgislation. Master Plans.

\section{Introdução}

Nas últimas décadas, questões relacionadas à qualidade de vida nas cidades ganharam amplitude, reflexo do adensamento populacional e do êxodo rural. Atrelados à inabilidade do planejamento urbano no país, tais reflexos acarretaram problemáticas espaciais, como as desigualdades socioeconômicas, a poluição do ar e das águas, congestionamentos e falhas no transporte público e a impermeabilidade do solo e enchentes (Lima et al., 2019).

Essa inabilidade é reflexo, em grande parte, do recorrente processo de mercantilização das cidades brasileiras, que interferiu diretamente na produção delas (Rolnik, 2015). Esse processo é movido por agentes ligados à esfera privada, que, historicamente, estão pactuados à gestão pública, fazendo com que leis e instrumentos regulatórios sejam negligenciados, interferindo, assim, na organização político-territorial das cidades. Assim, esses espaços passam a ser, gradualmente, uma mercadoria, e a influência do capital ganha destaque, regendo as dinâmicas urbanas - reproduzindo a segregação social e a fragmentação do espaço urbano (Vainer et al., 2000).

Desse modo, o planejamento urbano torna-se indispensável, e, por isso, diversas tratativas de organização territorial foram pensadas. Até a década de 1980, a solução apresentada pelos gestores públicos para regular o território foi a criação de planos de integração socioeconômicos e cidades funcionais, como a Lei oㅡ 6.766/79 - responsável pelo parcelamento do solo urbano no registro imobiliário (Brasil, 1979) -, que teve como finalidade ordenar o espaço urbano destinado à habitação, apresentando um importante papel para a sustentabilidade das cidades brasileiras. Contudo, esses planos não solucionaram embates entre grupos conflitantes e não romperam obstáculos impostos pela política exclusivamente voltada ao capital, sendo depostos por não solucionarem os conflitos socioeconômicos e territoriais (Villaça, 2001).

Assim, entre as décadas de 1980 e 1990, constituiu-se um significativo processo de articulação social, resultando na criação do Movimento Nacional pela Reforma Urbana (MNRU), que buscava a democratização do território, apresentando um conjunto de políticas públicas. Como resultado, deu-se a aprovação dos Artigos 182 e 183 da Constituição da República Federativa do Brasil, de 1988 relacionados ao capítulo II Da Política Urbana (Brasil, 1988) -, algo pioneiro na Constituição Federal, caracterizando o bem-estar dos habitantes e o planejamento como elementos indissociáveis da organização territorial.

Além disso, destacam-se a resolução Conama no 01/86 as Leis 6.803/80 (Brasil, 1980), 6.938/81 (Brasil, 1981) e o Projeto de Lei do Senado 181/1989 (Brasil, 1989), que foram de grande relevância 
para o surgimento de instrumentos de fiscalização, avaliação e mitigação ao meio ambiente e zonas urbanas, além de destacarem a necessidade de garantia da participação popular nas discussões de projetos de impacto urbano. Desse modo, a legislação brasileira passa a conjecturar um sistema de gestão pública/ambiental que fiscaliza o meio urbano/ambiental através de técnicas e participação pública na análise e discussão do território.

Na década de 1990, o MNRU torna-se o Fórum Nacional da Reforma Urbana e, a partir de então, procedeu-se uma grande evolução na legislação ambiental, possibilitando o surgimento de outros instrumentos, a exemplo da CONAMA 237/97 (Brasil, 1997), considerada um marco regulador das políticas ambientais responsáveis por estudos de impactos nas inúmeras atividades humanas no espaço, dando à esfera municipal a competência dessa fiscalização.

Nesse sentido, torna-se indispensável a definição de uma nova classe de impactos que interprenda uma análise de escalas municipais, aderindo à concepção de vizinhança - que torna-se complexa, pois não apresenta somente caráter urbanístico. Portanto, propõe-se o Estudo de Impaco de Vizinhança (EIV), originado no Projeto de Lei de Desenvolvimento Urbano, compilado pelo Conselho Nacional de Desenvolvimento Urbano - CNDU, em 1980.

Anteriormente à criação do EIV, muitos municípios brasileiros já empregavam instrumentos de análise de impactos aplicados à concessão de licenças urbanísticas, como Porto Alegre, que desde 1979 utiliza um instrumento denominado Estudo de Viabilidade Urbanística, um estudo prévio para a implantação de empreendimentos, e São Paulo e Rio de Janeiro, que na década de 1990 passaram a exigir nas suas Leis Orgânicas Municipais a apresentação do Relatório de Impacto de Vizinhança em grandes empreendimentos imobiliários e grandes edificações (Peres \& Cassiano, 2019).

Posteriormente, o Estatuto das Cidades (EC), com a Lei 10.257/2001 - considerado um marco legal para o desenvolvimento sustentável das cidades, através da regulamentação das normas gerais voltadas para política urbana e seus respectivos instrumentos, como o EIV, citado nos Artigos 36 a 38 -, foi normatizado (Brasil, 2001).

O Artigo 36 da referida Lei designa que os empreendimentos, tanto de caráter público quanto privado, que dependem de EIV para a obtenção de licenças urbanísticas devem ser definidos por lei municipal, apresentando comprometimento em abordar seus efeitos positivos e negativos.

Desta forma, o EIV deve ser executado de forma clara, sem subjetividades que possam beneficiar o interesse privado a despeito do coletivo. Sua amplitude deve ser total, porém não deve inviabilizar empreendimentos e/ou atividades de menor significância na região.

Subsequentemente, o Artigo 37 dessa Lei define a obrigatoriedade da publicidade dos documentos integrantes do EIV, possibilitando a consulta de todos os materiais utilizados para realização do estudo. Assim, ele responsabiliza o instrumento pela contemplação de questões relacionadas ao adensamento populacional, à alteração no uso e ocupação do solo, geração de tráfego, valorização imobiliária, e de questões sobre patrimônio cultural e natural, além de ventilação e iluminação urbana. Por fim, o Artigo 38 define que o EIV não substitui a realização e aprovação do Estudo de Impacto Ambiental (EIA).

De tal maneira, o EIV apresenta-se como um instrumento legal de gestão urbana, outorgando aos municípios a definição dos tipos de empreendimentos, dos quais serão exigidos estudos sobre os impactos de sua instalação, submetendo-os ao licenciamento das atividades e condicionando-os à observação de impactos em menor escala.

Esses instrumentos urbanísticos estabelecem uma forma de gestão social do espaço urbano, buscando reprimir desigualdades socioeconômicas, descrevendo e prevendo impactos que ocorrem em áreas urbanas em consequência de ações humanas (Lima et al., 2019). Essas manifestam-se em áreas de influência dos empreendimentos, que sofrem alterações que, muitas vezes, conflitam com o interesse da sociedade. Dentre os agentes de impactos decorrentes da instalação de empreendimentos, destacam-se os supermercados, grandes edifícios e shopping centers, que, por exemplo, refletem na 
alteração de todo sistema de tráfego de veículos, podendo causar congestionamentos, a diminuição da capacidade do transporte público e a insuficiência no escoamento de vias, alterando o padrão urbanístico local. Portanto, observa-se que a instalação de empreendimentos sem estudos prévios pode levar a problemas urbanos, visto sua vasta característica transformadora.

À vista disso, o EIV permite a identificação de impactos anteriormente à proposta de ocupação. Ademais, tal estudo apresenta-se como um instrumento de caráter político e regulatório no planejamento municipal, atenuando desigualdades e relativizando impactos de empreendimentos. Destaca-se também por seu cunho preventivo - relacionado à análise prévia e particular de cada caso, utilizando a concessão de licenças ou a autorização de construção de empreendimentos considerados incômodos pela legislação municipal. Assim, o EIV aborda três questões cruciais que permitem seu entendimento: os aspectos jurídicos, os técnicos e os administrativos, conceituados como perspectivas constituintes da gestão democrática dos municípios (Peres \& Cassiano, 2017).

Para sua elaboração, é necessário definir critérios, como: caracterização do empreendimento; cálculo da área de influência; impactos esperados e medidas mitigadoras compensatórias (Schvarsberg et al., 2016). Para sua efetividade no desenvolvimento urbano, o EIV deve estar apoiado em legislações urbanas bem elaboradas e estruturadas, conforme o PD, a fim de fornecer aos gestores públicos um importante instrumento de gestão, espelhando a compatibilidade do empreendimento, a capacidade de infraestrutura urbana e seus aspectos, aspirando à efetivação do vínculo do cidadão com as cidades, condicionando espaços para discussões e debates (Silva \& Lollo, 2013).

A definição da área de abrangência do empreendimento é importante, pois demonstra sua área de influência, podendo restringi-la apenas a terrenos e lotes, ou a quarteirões do seu entorno, além de evidenciar os impactos no trânsito e a circulação de veículos (Schvarsberg et al., 2016). Essa definição deve ser estudada especificamente, examinando cada particularidade espacial. Para tal, é essencial a utilização de base de dados confiáveis, dos PD e outros serviços oferecidos por órgãos públicos municipais.

Uma vez definidas a área de influência do empreendimento e a metodologia para levantamento de dados, devem ser realizados diagnósticos urbanos, com a finalidade de registrar resultados do estudo e medidas compensatórias, verificando impactos e avaliando a efetividade do EIV. Esse diagnóstico abrange questões socioeconômicas, urbanísticas e infraestruturais, e se apresenta como um instrumento de gestão democrática, atrelando os resultados apresentados entre os técnicos elaboradores do estudo e a sociedade.

Dentre as razões que dificultam as normatizações dispostas no EC, destacam-se a falta de aplicabilidade dos seus instrumentos, somada à incapacidade técnica das secretarias municipais, além da desarticulação entre os PD e o direcionamento de investimentos (Brajato \& Denaldi, 2019).

O EIV também apresenta como problema o frequente adiamento da execução e da legislação nos locais de regulamentação dos empreendimentos, fruto da falta de estruturação de equipes técnicas para o planejamento de tais estudos (Lollo \& Rohm, 2005) e da negligência das administrações municipais em questões referentes ao EIV, resultando na falta do real direito da população de contribuir no processo de implantação de empreendimentos que modificam o espaço em que atuam. A falta da avaliação das condições de instalação resultam em consequências negativas para a população local.

Portanto, observa-se que sua regulamentação deve municiar os procedimentos de forma objetiva e transparente quanto a sua publicidade, assim como sua relação entre a etapa administrativa e participativa, detalhando seu desenvolvimento e possibilitando melhor mensuração e quantificação de impactos.

Desse modo, em 2016, foi lançado o Caderno Técnico de Regulamentação e Implementação do EIV, através do Programa Nacional de Capacitação das Cidades (PNCC) - importante material para os 
setores que atuam com o EIV -, renovado em 2017. Entre 2018 e 2019, o PNCC ofereceu cursos sobre os instrumentos integrantes do EC.

Todavia, na prática, observam-se embates por parte dos empreendedores na elaboração do EIV, devido, muitas vezes, a interesses conflitantes, como a especulação imobiliária, o aumento da informalidade urbana, conflitos fundiários e desarticulação de conselhos municipais. Frequentemente observa-se a disputa entre agentes imobiliários e a legislação local, como no caso do Projeto Nova Recife - um empreendimento de 13 torres de até 40 metros de altura na capital pernambucana, que foi aprovado sem nenhuma realização de EIV, contrariando a legislação municipal, ignorando possíveis impactos relacionados ao projeto e as medidas mitigadoras (Correia, 2012).

A avaliação de impactos relacionados aos empreendimentos imobiliários apresenta desafios metodológico-operacionais, visto a alteração dos padrões de ocupação do solo, e provoca efeitos como a verticalização e horizontalização. Entretanto, observa-se comumente a relação entre órgãos públicos e agentes do mercado financeiro na gestão urbana (Rolnik, 2015), resultando em, muitas vezes, uma legislação que negligencia aspectos referentes à qualidade de vida e à regulação democrática do espaço.

Assim, o objetivo deste trabalho foi, através do estudo das legislações referentes ao EIV nos municípios de médio porte no Estado de São Paulo, realizar uma abordagem quantitativa, envolvendo pesquisas bibliográficas, documentais e análises de caso, buscando constatar a situação desse instrumento no PD de tais municípios, analisando possíveis reflexos e perspectivas na sua organização e aplicação.

\section{Legislação referente ao Estudo de Impacto de Vizinhança nos municípios paulistas de médio porte ( 100 mil a 400 mil habitantes)}

Conforme observado anteriormente, diversos são os problemas encontrados na elaboração e legislação referente ao EIV nos municípios, independentemente de sua proporcionalidade populacional. 0 sudeste é a região mais populosa do Brasil, e o Estado de São Paulo possui a maior concentração populacional do território nacional, com 44.507.964 habitantes em 645 municípios (SEADE, 2020). Os municípios paulistas, assim como suas legislações referentes aos instrumentos constantes no EC, são heterogêneos, com especificidades socioeconômicas e legislativas.

Para definição de uma escala de análise significativa da legislação sobre EIV que aborde com significância os municípios paulistas, foi necessário restringi-los a uma representação por "porte dos municípios", aqueles com população entre 100.000 e 400.000 habitantes. A justificativa dessa escala é a representatividade deles em questões sociais, econômicas e populacionais no estado, visto que totalizam 70 municípios $(9,30 \%$ da totalidade).

Além disso, esses municípios configuram 26,64\% da concentração populacional estadual, com 11.858.403 habitantes, e, conforme o EC, todo e qualquer município que apresente população acima de 20.000 habitantes tem obrigatoriedade de possuir um PD, assumindo seu compromisso de renovação a cada década.

Todavia, muitas vezes esse compromisso de renovação não é respeitado pelos municípios. No caso dos levantados no presente artigo, 35 não possuem seus PD atualizados, com alguns apresentando desatualização de 20 anos, como no caso de Cubatão, Leme e São Vicente. Este último representa um caso particular, visto que seu PD é do ano de 1999, anterior à regulamentação do EC, responsável somente por disciplinar a ocupação do solo no município. Leme está em processo de atualização do PD, pois o anterior data de 1994 e também oferece somente caráter disciplinador na regulação espacial.

Dentre todos os municípios estudados, $60 \%$ estão com seus PD desatualizados - uma porcentagem significativa, muitas vezes atribuída à influência de agentes privados na escala pública, o que pode causar a negligência na elaboração e atualização dos PD (Villaça, 2001; Rolnik, 2015). A seguir, a Tabela 1 apresenta os municípios, sua população, o ano do PD vigente e a conformidade com a Lei 10.257. 
Tabela 1 - Municípios paulistas de médio porte, sua população, ano do PD vigente e conformidade com a Lei 10.257

\begin{tabular}{|c|c|c|c|}
\hline Municípios & População & Ano do Plano Diretor & Conformidade com a Lei 10.257 \\
\hline Leme & 100.069 & 1994 & Não \\
\hline Assis & 100.781 & 2006 & Não \\
\hline Ourinhos & 109.763 & 2018 & Sim \\
\hline Salto & 114.389 & 2006 & Não \\
\hline Poá & 114.625 & 2006 & Não \\
\hline Caraguatatuba & 114.648 & 2011 & Sim \\
\hline Itatiba & 116.365 & 2011 & Sim \\
\hline Catanduva & 116.819 & 2006 & Não \\
\hline Guaratinguetá & 117.060 & 2006 & Não \\
\hline Barretos & 117.509 & 2006 & Não \\
\hline Ribeirão Pires & 118.441 & 2014 & Sim \\
\hline Votorantim & 118.727 & 2015 & Sim \\
\hline Tatuí & 118.833 & 2006 & Não \\
\hline Várzea Paulista & 119.172 & 2006 & Não \\
\hline Birigui & 120.138 & 2006 & Não \\
\hline Sertãozinho & 121.229 & 2008 & Não \\
\hline Jandira & 122.053 & 2006 & Não \\
\hline Cubatão & 128.108 & 1998 & Não \\
\hline Araras & 129.861 & 2006 & Não \\
\hline Santana de Parnaíba & 135.194 & 2006 & Não \\
\hline Atibaia & 138.351 & 2006 & Não \\
\hline Botucatu & 139.856 & 2017 & $\operatorname{sim}$ \\
\hline Jaú & 145.940 & 2010 & Sim \\
\hline Mogi Guaçu & 147.259 & 2015 & Sim \\
\hline Franco da Rocha & 150.151 & 2015 & Sim \\
\hline São Caetano do Sul & 151.116 & 2015 & Sim \\
\hline Itapetininga & 158.553 & 2015 & Sim \\
\hline Pindamonhangaba & 162.051 & 2006 & Não \\
\hline Bragança Paulista & 162.402 & 2007 & Não \\
\hline Itapecirica da Serra & 167.916 & 2006 & Não \\
\hline ItU & 168.252 & 2006 & Não \\
\hline Cotia & 170.507 & 2014 & $\operatorname{sim}$ \\
\hline Francisco Morato & 172.283 & 2006 & Não \\
\hline $\begin{array}{l}\text { Santa Bárbara } \\
\text { d'Oeste }\end{array}$ & 187.926 & 2017 & Não \\
\hline $\begin{array}{l}\text { Ferraz de } \\
\text { Vasconcelos }\end{array}$ & 190.519 & 2006 & Sim \\
\hline $\begin{array}{l}\text { Rio Claro } \\
\text { Riscons }\end{array}$ & 199.765 & 2017 & Sim \\
\hline Presidente Prudente & 219.805 & 2018 & Sim \\
\hline Araraquara & 225.997 & 2014 & Sim \\
\hline Jacareí & 226.355 & 2003 & Não \\
\hline Hortolândia & 226.426 & 2008 & Não \\
\hline Marília & 230.154 & 2006 & Não \\
\hline Americana & 231.361 & 2018 & $\mathrm{Sim}$ \\
\hline Itapevi & 233.816 & 2008 & Não \\
\hline Indaiatuba & 239.391 & 2010 & Sim \\
\hline São Carlos & 240.706 & 2018 & Sim \\
\hline Barveri & 262.207 & 2009 & Sim \\
\hline Embu das Artes & 267.771 & 2012 & Sim \\
\hline Sumaré & 279.151 & 2006 & Não \\
\hline Taboão da Serra & 279.902 & 2006 & Não \\
\hline Suzano & 288.115 & 2017 & Sim \\
\hline Limeira & 294.392 & 2009 & Sim \\
\hline Taubaté & 304.596 & 2017 & Sim \\
\hline Praia Grande & 311.480 & 2016 & Sim \\
\hline Guarujá & 313.756 & 2013 & Sim \\
\hline Franca & 353.187 & 2003 & Não \\
\hline São Vicente & 355.542 & 1999 & Não \\
\hline Bauru & 362.348 & 2008 & Não \\
\hline Itaquaquecetuba & 365.490 & 2006 & Não \\
\hline Piracicaba & 387.507 & 2006 & Não \\
\hline Carapicuíba & 392.297 & 2011 & Sim \\
\hline
\end{tabular}

Fonte: SEADE (2020), AMERICANA (2018), ARARAQUARA (2014), ARARAS (2006), ASSIS (2016), ATIBAIA (2006), BARRETOS (2006), BARUERI (2008), BIRIGUI (2006), BOTUCATU (2017), BRAGANÇA PAULISTA (2007), CARAGUATATUBA (2011), CARAPIBUÍBA (2011), CATANDUVA (2006), COTIA (2014), CUBATÃO (1999), EMBU DAS ARTES (2012), FERRAZ DE 
VASCONCELOS (2006), FRANCA (2003), FRANCISCO MORATO (2006), FRANCO DA ROCHA (2015), GUARATINGUETÁ (2006), GUARUJÁ (2013), HORTOLÂNDIA (2008), INDAIATUBA (2010), ITAPECIRICA DA SERRA (2006), ITAPETININGA (2015), ITAPEVI(2008), ITAQUAQUECETUBA (2006), ITATIBA (2011), ITU (2006), JACARÉ (2003), JANDIRA (2006), JAÚ (2010), LEME (1994), LIMEIRA (2009), MARÍLIA (2006), MOGI GUAÇU (2015), OURINHOS (2018), PINDAMONHANGABA (2006), PIRACICABA (2006), POÁ (2006), PRAIA GRANDE (2016), PRESIDENTE PRUDENTE (2018), RIBEIRÃO PIRES (2014), RIO CLARO (2017), SALTO (2016), SANTA BARBARA D'OESTE (2017), SANTANA DO PARNAÍBA (2006), SÃO CAETANO DO SUL (2015), SÃO CARLOS (2018), SÃO VICENTE (1999), SERTÃOZINHO (2008), SUMARÉ (2006), SUZANO (2017), TABOÃO DA SERRA (2006), TATUÍ (2006), TAUBATÉ (2017), VÁRZEA PAULISTA (2006), VOTORANTIM (2015).

O EIV é um instrumento de extrema importância, presente nos Artigos 36, 37 e 38, da Lei 10.257, sendo um instrumento essencial para mitigar impactos negativos na instalação de empreendimentos. Entretanto, esses artigos são apenas conceitos básicos referentes ao EIV, e cabe a cada município discorrer sua própria legislação referente ao tema, norteando-se apenas na referida Lei, adapando-a a sua realidade, especificidades e particularidades.

Pode-se observar que determinados municípios, como Leme, Cubatão, São Caetano do Sul, Itapecerica da Serra, Cotia, Franca, São Vicente e Itaquaquecetuba não fazem nenhuma menção ao EIV no seu PD, representando um número considerável de 13,3\% da totalidade estudada. Existe também o caso dos municípios que possuem uma legislação defasada ou antiquada em relação à proposta do EC, refletindo em conflitos e inconsistências legislativas ligadas à instalação de empreendimentos. São eles o município de Itu, Francisco Morato e Araraquara, representando 5\% da totalidade.

Os municípios de Ourinhos, Sertãozinho, Jaú, Mogi Guaçu, Ferraz de Vasconcelos, Indaiatuba e Barueri (11,65\% da totalidade estudada) possuem em seus PD apenas uma cópia dos Artigos 36 a 38 da Lei 10.257/2001. O principal reflexo disso é uma legislação referente ao EIV precarizada, que pode resultar em contradições na instalação de empreendimentos, uma vez que esses artigos não consideram aspectos particulares de cada município, como a população, os tamanhos dos lotes onde será necessária a realização do EIV e suas próprias Leis de Zoneamento Urbano. Desses 15 municípios analisados, 10 possuem entre 100.000 e 200.000 habitantes, demonstrando maior negligência na elaboração do EIV em muncípios menos populosos avaliados no trabalho.

Várzea Paulista, Santana de Parnaíba, Atibaia, Hortolândia, Itapevi e Praia Grande e Salto (que unem o Estudo de Impacto de Vizinhança e o Estudo de Impacto Ambiental em um só parágrafo), totalizam $11,65 \%$ de municípios cujas legislações apenas mencionam o EIV, não possuindo nenhuma seção específica para esse instrumento nem fazendo ao menos menções aos Artigos 36 a 38 do EC. Nesse caso, a falta de especificidade apresentada nos PD inclui uma legislação falha e não abrangente relacionada à instalação de empreendimentos, acarretando a falta de medidas mitigadoras relacionadas a ruídos, vibração, respeito ao zoneamento urbano, fluxo de veículos, etc.

Ocorrem também casos em que os municípios apresentam artigos complementares aos Artigos 36 a 38 do EC, nos quais cada um realiza suas respectivas ressalvas legislativas, respeitando suas particularidades. É importante ressaltar que essa classe apresenta melhores condicionantes para receber a instalação de empreendimentos em suas espacialidades. Esses municípios são: Assis, Poá, Caraguatatuba, Itatiba, Catanduva, Guaratinguetá, Barretos, Ribeirão Pires, Votorantim, Tatuí, Várzea Paulista, Birigui, Jandira, Araras, Botucatu, Franco da Rocha, Itapetininga, Pindamonhangaba, Bragança Paulista, Santa Bárbara d'Oeste, Rio Claro, Presidente Prudente, Jacareí, Americana, São Carlos, Embu das Artes, Sumaré, Marília, Taboão da Serra, Suzano, Limeira, Taubaté, Guarujá, Bauru, Piracicaba e Carapicuíba, totalizando aproximadamente $60 \%$ dos munícipios estudados. A Tabela 2 apresenta os municípios, as classes estabelecidas referentes ao EIV e sua legislação, e a Figura 1 ilustra a proporção da situação dos EIV nos PD desses municípios. 
Tabela 2 - Municípios paulistas de médio porte e a situação do EIV no PD

\begin{tabular}{|c|c|c|c|c|c|}
\hline Municípios & $\begin{array}{l}\text { Cópia dos Artigos } \\
36 \text { a } 38 \text { do } M C\end{array}$ & $\begin{array}{l}\text { Artigos complementares } \\
\text { ao MC }\end{array}$ & $\begin{array}{l}\text { Nenhuma legislação } \\
\text { referente ao EIV }\end{array}$ & $\begin{array}{l}\text { Fazem menção ao EV, mas sem } \\
\text { seção destinado ao mesmo }\end{array}$ & $\begin{array}{l}\text { Legislação defasada } \\
\text { em relação ao MC }\end{array}$ \\
\hline Leme & & & $\mathrm{X}$ & & \\
\hline Assis & & $x$ & & & \\
\hline Ourinhos & $x$ & & & & \\
\hline Salto & & & & $x$ & \\
\hline Poá & & $x$ & & & \\
\hline Caraguatatuba & & $x$ & & & \\
\hline Itatiba & & $\mathrm{x}$ & & & \\
\hline Catanduva & & $x$ & & & \\
\hline Guaratinguetá & & $x$ & & & \\
\hline Barretos & & $x$ & & & \\
\hline Ribeirão Pires & & $x$ & & & \\
\hline Votorantim & & $x$ & & & \\
\hline Tatuí & & $x$ & & & \\
\hline Várzea Paulista & & $x$ & & & \\
\hline Birigui & & $x$ & & & \\
\hline Sertãozinho & $x$ & & & & \\
\hline Jandira & & $x$ & & & \\
\hline Cubatão & & & $x$ & & \\
\hline Araras & & $x$ & & & \\
\hline Santana de Parnaíba & & & & $x$ & \\
\hline Atibaia & & & & $x$ & \\
\hline Botucatu & & $x$ & & & \\
\hline Jaú & $x$ & & & & \\
\hline Mogi Guaçu & $x$ & & & & \\
\hline Franco da Rocha & & & & & \\
\hline São Caetano do Sul & & & $x$ & & \\
\hline Itapetininga & & $x$ & & & \\
\hline Pindamonhangaba & & $x$ & & & \\
\hline Bragança Paulista & & $x$ & & & \\
\hline Itapecirica da Serra & & & & $x$ & \\
\hline Itu & & & & & $x$ \\
\hline Cotia & & & & $x$ & \\
\hline Francisco Morato & & & & & $x$ \\
\hline Santa Bárbara d'Oeste & & $x$ & & & \\
\hline Ferraz de Vasconcelos & $x$ & & & & \\
\hline Rio Claro & & $x$ & & & \\
\hline Presidente Prudente & & $x$ & & & \\
\hline Araraquara & & & & & $x$ \\
\hline Jacareí & & $x$ & & & \\
\hline Hortolândia & & & & $x$ & \\
\hline Marília & & & & & \\
\hline Americana & & $x$ & & & \\
\hline Itapevi & & $x$ & & & \\
\hline Indaiatuba & $x$ & & & $x$ & \\
\hline São Carlos & & $x$ & & & \\
\hline Barueri & $x$ & & & & \\
\hline Embu das Artes & & & & $x$ & \\
\hline Sumaré & & & & $x$ & \\
\hline Taboão da Serra & & & & $x$ & \\
\hline Suzano & & & & $x$ & \\
\hline Limeira & & & & $x$ & \\
\hline Taubaté & & & & $x$ & \\
\hline Praia Grande & & & & $x$ & \\
\hline Guarujá & & $x$ & & & \\
\hline Franca & & & $x$ & & \\
\hline São Vicente & & & $x$ & & \\
\hline Bauru & & $x$ & & & \\
\hline Itaquaquecetuba & & & $x$ & & \\
\hline Piracicaba & & $x$ & & & \\
\hline Carapicuíba & & $\mathrm{x}$ & & & \\
\hline
\end{tabular}

Fonte: Autores (2020). 


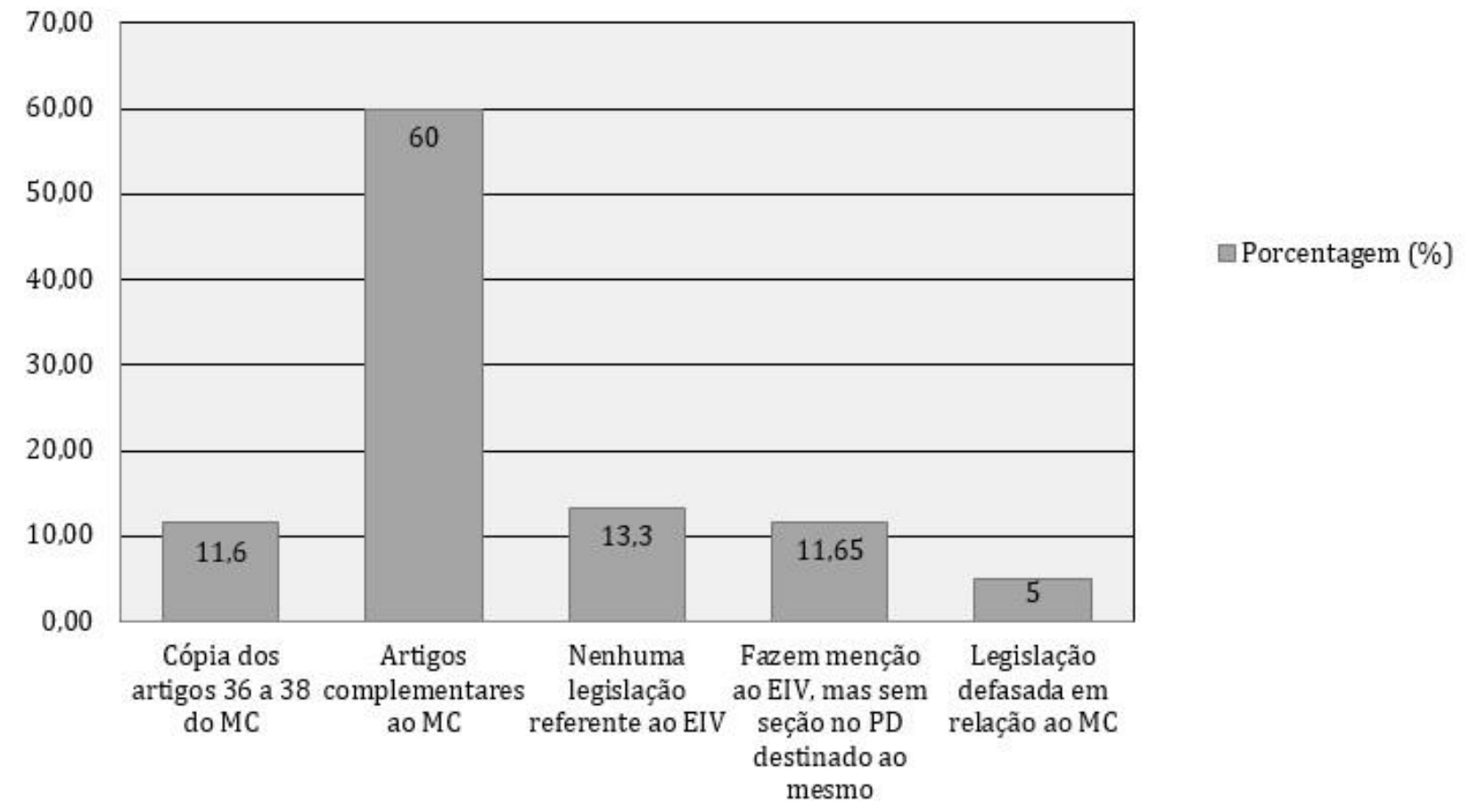

Figura 1 - Proporção da situação dos EIV nos PD nos municípios. Fonte: Autores (2020).

Dentre todos os PD analisados, destacam-se os municípios de Taubaté, Sumaré, Americana, Rio Claro e Santa Bárbara d'Oeste, devido às suas especificidades ao citar o EIV. O PD de Taubaté, além de referenciar e explicitar os artigos do EC, realiza detalhamentos na legislação referentes ao EIV, elucidando-o em vários segmentos, como nos Capítulos I, voltado ao Zoneamento Municial (com subseções ligadas ao desenvolvimento socioeconômico, com o EIV auxiliando a classificação de usos do solo), V e VI, destinados à indústria e ao desenvolvimento social. O diferencial desse PD é a existência de uma seção relacionada à aplicabilidade do EIV e aos agentes responsáveis pela realização e avaliação do empreendimento, além de uma tabela indicando "Níveis de Incomodidade" em empreendimentos nos quais há necessidade de elaboração de EIV.

Americana apresenta uma legislação referente ao EIV semelhante à de Taubaté em seu PD. Contudo, o que diversifica seu PD dos demais é a determinação de "níveis de impacto", classificando-os como "baixo, médio e alto" de acordo com os diferentes condicionantes para implantação de empreendimentos, conforme a adequação dos mesmos nesses níveis. 0 Art. 199 do PD também elucida a forma de aplicação do EIV pelos agentes responsáveis pelo empreendimento, além do Art. 200, que fomenta a obrigatoriedade de esses estudos serem realizados em conjunto com órgãos públicos municipais. Por fim, o Art. 218 legitima a publicidade desses estudos, garantindo sua anexação em jornais e revistas municipais, visando a uma gestão que integre órgãos públicos e municipais.

Embora Sumaré não apresente tanta descrição referente ao EIV no seu PD, destaca-se o Art. 100, pois nele é dada a obrigatoriedade da opinião pública sobre o EIV dos empreendimentos, além da disponibilização de todos os relatórios referentes ao EIV na página oficial da Prefeitura Municipal. Embora esse caráter seja obrigatório no Art. 37 do ED, somente Sumaré apresenta uma parte do PD dedicada a legitimar a publicidade desses estudos, algo importantíssimo para a gestão das cidades, visto que a conexão entre a população e os órgãos fiscalizadores é de suma importância para a integração entre essas condicionantes.

O município de Rio Claro apresenta em seu PD artigos e parágrafos semelhantes aos explanados até aqui, possuindo uma seção destinada ao estudo do EIV que detalha condições necessárias para a instalação de cada tipo de empreendimento. Além dessa seção, é possível encontrar citações sobre EIV em todo o PD. O diferencial desse PD, atrelado ao EIV, refere-se ao Anexo XVI, responsável por 
destacar o roteiro de informações para elaboração do EIV. Esse anexo é importante, pois deixa claro ao agente empreendedor a forma como o EIV deve ser aplicado, impedindo ambiguidades na sua elaboração, fator recorrente, observado na introdução deste trabalho.

O caso de Santa Bárbara d'Oeste é diferente quando comparado aos outros. Embora seu PD não apresente o EIV ao longo do texto, o Art. 96, no Capítulo VIII, exibe uma tabela que estabelece a extensão de cada uso do solo, regulamentando a elaboração do EIV. Isso é importante, pois evidencia que o município adequou o proposto no EC às suas condições específicas.

\section{Perspectivas nas alterações do EIV nesses municípios}

Embora presentes nos Artigos 36 a 38 da Lei 10.257/2001, é possível observar que diversos municípios não apresentam instrumentos suficientes para substituir a aplicação do EIV em sua área urbanizada. Isso ocorre devido à negligência de órgãos fiscalizadores municipais, atrelada a interesses de agentes privados na organização territorial, conforme Rolnik (2015) e Correia (2012). A insuficiência de legislação relacionada a esse tema reflete em disparidades socioeconômicas no espaço urbano e gera conflitos entre esses agentes e a sociedade, além de causar problemáticas na instalação de empreendimentos nos municípios, como problemas no fluxo de automóveis, iluminação, emissão de ruídos e vibração e mudanças no uso e ocupação do solo.

Uma possível solução para essas questões é a regulamentação das avaliações de impacto, que facilitaria a regulamentação dos EIV nos municípios (Peres \& Cassiano, 2017) e implicaria a melhoria da elaboração de PD e a simplificação da aplicação do EIV, além de oferecer diretrizes gerais e moldes de implementação aos órgãos públicos e agentes empreendedores como uma alterantiva acessível à regulação do espaço urbano, desvinculando-o de agentes privados.

Outra alternativa seria a autoaplicabilidade do EIV em função dos seus princípios constitucionais (Peres \& Cassiano, 2017), o que possibilitaria sua aplicação independentemente de sua existência ou menção no PD. Dessarte, salienta-se a necessidade de estabelecer, através de Conselhos Estaduais e Municipais, juntamente com a participação da população, padrões e critérios básicos a serem seguidos para que essa aplicação ocorra.

Os municípios de Assis, Poá, Caraguatatuba, Itatiba, Catanduva, Guaratinguetá, Barretos, Ribeirão Pires, Votorantim, Tatuí, Várzea Paulista, Birigui, Jandira, Araras, Botucatu, Franco da Rocha, Itapetininga, Pindamonhangaba, Bragança Paulista, Presidente Prudente, Jacareí, São Carlos, Embu das Artes, Sumaré, Marília, Taboão da Serra, Suzano, Guarujá, Bauru, Piracicaba e Carapicuíba apresentam legislação complementar aos Artigos 36 a 38 do EC, entretanto não apresentam as soluções estipuladas por Peres \& Cassiano (2017), tendo caráter insatisfatório em relação à aplicabilidade do EIV.

Por outro lado, os municípios de Taubaté, Sumaré, Americana, Rio Claro e Santa Bárbara d’Oeste apresentam essas regulamentações de impacto e diretrizes. Nesse sentido, é importante salientar que esses municípios contêm populações heterogêneas, com 304.596, 279.151, 231.361, 199.765 e 187.926 habitantes respectivamente, demonstrando que a populosidade não interfere na elaboração de uma legislação contundente em relação ao EIV no PD.

Os municípios de Itapevi, Ferraz de Vasconcelos e Leme estão com seus PD em fase de revisão. Nesse sentido, espera-se que, nesses locais, a legislação referente ao EIV seja abrangente, detalhada e que desconsidere o interesse de agentes privados na organização espacial, para que esse instrumento seja importante na mitigação dos impactos dos empreendimentos locais.

Salto, Várzea Paulista, Santana de Parnaíba, Atibaia, Hortolândia, Itapevi e Praia Grande fazem apenas menção ao EIV no seus PD, enquanto Ourinhos, Sertãozinho, Jaú, Mogi Guaçu, Ferraz de Vasconcelos, Indaiatuba e Barueri apresentam cópias dos Artigos 36 a 38 do EC. Logo, 23,3\% da totalidade dos municípios não possui nenhuma legislação específica referente ao EIV, resultando em, muitas vezes, empreendimentos que não apresentam relatórios com medidas mitigadoras, fruto da 
falta de especificidade de legislação municipal e da mercantilização das cidades (Vainer et al., 2000), o que pode ocasionar problemáticas urbanas.

Enfim, os municípios de Leme, Cubatão, São Caetano do Sul, Itapecerica da Serra, Cotia, Franca, São Vicente e Itaquaquecetuba não apresentam legislação referente ao EIV em seu PD, o que resulta na inexistência de políticas públicas atenuadoras de impactos relacionados à instalação de empreendimentos e, consequentemente, em um espaço heterogêneo e conflituoso.

\section{Conclusões}

Nos municípios de médio porte do estado de São Paulo, observa-se que a maioria possui ao menos uma menção ao EIV em seu PD, mesmo que seja apenas uma cópia do que foi preestabelecido pelo EC. Ainda existem os casos dos municípios que apresentam legislação complementar ao proposto pelo EC, com itens e artigos complementares na sua legislação, que dizem respeito, muitas vezes, a condicionantes exclusivas de cada município.

Nota-se também uma grande quantidade de municípios que não apresentam nenhum item referente ao EIV, tampouco uma seção específica sobre tal instrumento. A ausência dessa legislação pode resultar, muitas vezes, em um desenvolvimento urbano desigual e com problemáticas socioeconômicas.

Assim, é importante debater o aperfeiçoamento do EIV como instrumento, repensando aprimoramentos metodológicos para sua aplicação e considerando as particularidades municipais para sua elaboração. Alguns municípios apresentados já possuem essas alternativas em seu PD, como no caso de Taubaté, Sumaré, Americana, Rio Claro e Santa Bárbara d'Oeste.

Desse modo, observa-se que o EIV é uma importante alternativa para o ordenamento e para a gestão territorial urbana. Neste trabalho, observou-se que a falta de efetivação desse pelas prefeituras causa impactos em sua aplicabilidade. Tal lacuna pode influenciar a tomada de decisão sobre a instalação do empreendimento e, por vezes, priorizar o bônus econômico em detrimento do ônus socioambiental. Portanto, é necessário olhar esse instrumento de forma integrada aos demais instrumentos da política urbana, que, quando trabalhados conjuntamente, auxiliam na gestão, no controle territorial e na busca tanto da diminuição dos impactos negativos quanto do desenvolvimento sustentável das cidades.

Por fim, o EIV deve ser observado como um instrumento regulador do espaço urbano, um mediador de conflitos de ordem política e social. Ademais, cabe ao corpo técnico e aos gestores públicos reconhecer o papel do EIV nos processos de uso e ocupação do território, considerando-o uma alternativa para a melhora da gestão urbana do país.

\section{Referências}

Americana (2018, 21 de dezembro). Lei n. 6.264, de 21 de dezembro de 2018. Dispõe sobre o Plano Diretor de Desenvolvimento Físico e Urbanístico do Município de Americana - PDFU, e dá outras providências. Americana: Portal da Prefeitura de Americana.

Araraquara (2014, 20 de outubro). Lei Complementar n. 858, de 20 de outubro de 2014. Altera a Lei Complementar n. 850/2014 no que é pertinente ao uso e ocupação do solo, altera a Lei Complementar 851/2014, altera a Lei 8,229/2014 e altera o Decreto 10,666/14 e dá outras providências. Araraquara: Portal da Prefeitura de Araraquara.

Araras (2006, 06 de outubro). Lei Complementar n. 3901, de 06 de outubro de 2006. Dispõe sobre o Plano Diretor do Município de Araras, suas normas disciplinadoras e dá outras providências. Araras: Portal da Prefeitura de Araras.

Assis (2006, 10 de outubro). Lei Complementar n. 10, de 10 de outubro de 2006. Institui sobre o Plano Diretor do Município de Assis e dá outras previdências. Assis: Portal da Prefeitura de Assis.

Atibaia (2006, 11 de janeiro). Lei Complementar n. 496/06, de 11 de janeiro de 2006. Dispõe sobre o proceso de planejamento permanente do Município, sobre a participação comunitária, sobre o regime e a inserção na ordem 
administrativa do Plano Diretor e dos demais planos que o integram, e dá outras providências. Atibaia: Portal da Prefeitura de Atibaia.

Barretos (2006, 10 de outubro). Lei Complementar n. 73, de 10 de outubro de 2006. Institui o Plano Diretor de Barretos e dá outras providências. Barretos: Portal da Prefeitura de Barretos.

Barueri (2009, 18 de dezembro). Lei Complementar n. 245, de 18 de dezembro de 2009. Altera e Consolida a Lei Complementar n. 175, de 12 de dezembro de 2006. Barueri: Portal da Prefeitura de Barueri.

Bauru (2008, 22 de agosto). Lei 5.631, de 22 de agosto de 2008. Institui o Plano Diretor Participativo do Município de Bauru. Bauru: Portal da Prefeitura de Bauru.

Birigui (2006, 10 de outubro). Lei Complementar n. 17, de 10 e outubro de 2006. Institui o Plano Diretor Participativo de Birigui e dá outra providências. Birigui: Portal da Prefeiura de Birirgui.

Botucatu (2017). Lei Complementar n. 1224/2017. Dispõe sobre o Plano Diretor participativo do Município de Botucatu e dá outras providências. Botucatu: Portal da Prefeitura de Botucatu.

Bragança Paulista (2007, 16 de abril). Lei Complementar n. 534, de 16 de abril de 2007. Aprova o Plano Diretor do Município de Bragança Paulista, dispõe sobre o sistema municipal de planejamento e dá outras providências. Bragança Paulista: Portal da Prefeitura de Bragança Paulista.

Brajato, D., \& Denaldi, R. (2019). 0 impasse na aplicação do Estatuto da Cidade: explorando o alcance da PEUC em Maringá - PR (2009-2015). Revista Brasileira de Estudos Urbanos e Regionais, 21(1), 45-62.

doi: https://doi.org/10.22296/2317-1529.2019v21n1p45.

Brasil (1979, 19 de dezembro). Lei n. 6.766 de 19 de dezembro de 1979. Dispõe sobre o Parcelamento do Solo Urbano e dá outras Providências. Brasília: Diário Oficial da União.

Brasil (1980, 02 de julho). Lei n. 6.803 de 02 de julho de 1980. Dispõe sobre as diretrizes básicas para o zoneamento industrial nas áreas críticas de poluição, e dá outras providências. Brasília: Diário Oficial da União.

Brasil (1981, 31 de agosto). Lei n.6.938, de 31 de agosto de 1981. Dispõe sobre a Política Nacional do Meio Ambiente, seus fins e mecanismos de formulação e aplicação, e dá outras providências. Brasília: Diário Oficial da União.

Brasil (1986, 23 de janeiro). Resolução CONAMA n. 1. Dispõe sobre os critérios básicos e diretrizes gerais para a avaliação de impacto ambiental. Brasília. Diário Oficial da União.

Brasil (1988, 05 de outubro). Constituição da República Federativa do Brasil, de 05 de outubro de 1988. Brasília: Diário Oficial da União.

Brasil (1989, 28 de junho). Projeto de Lei do Senado n. 181 de 28 de junho de 1989. Estabelece Diretrizes Gerais da Política Urbana e dá outras providências. Brasília. Diário Oficial da União.

Brasil (1997, 19 de dezembro). Resolução CONAMA n. 237. Dispõe sobre o licenciamento ambiental: competência da União, Estados e Municípios; listagem de atividades sujeitas ao licenciamento; Estudos Ambientais, Estudo de Impacto Ambiental e Relatório de Impacto Ambiental. Brasília: Diário Oficial da União,

Brasil (2001, 10 de junho). Lei n. 10.257, de 10 de junho de 2001. Regulamenta os arts. 182 e 183 da Constituição Federal,estabelecem diretrizes gerais da política urbana e dá outras providências. Brasília: Diário Oficial da União, seção 1.

Caraguatatuba (2011, 24 de novembro). Lei Complementar n. 42, de 24 de novembro de 2011. Dispõe sobre o Plano Diretor do Município da Estância Balneária de Caraguatatuba e dá outras providências. Caraguatatuba. Portal da Prefeitura de Caraguatatuba.

Carapicuíba (2011, 28 de abril). Lei n. 3074, de 28 de abril de 2011. Institui o Plano Diretor Participativo e Sistema de Planejamento Integrado de Gestão Participativa no Município de Carapicuíba, nos termos dos artigos 182 e 183 da Constituição Federal, do Capítulo III da Lei Federal n. 10.257, de 10 de julho de 2001 - Estatuto da Cidade e Lei Orgânica de Carapicuíba. Carapibuíba: Portal da Prefeitura de Carapicuíba.

Catanduva (2006, 26 de dezembro). Lei n.0355, de 26 de dezembro de 2006. Institui o Plano Diretor Participativo, a lei de uso e ocupação do solo e a lei de parcelamento do solo do município de Catanduva e dá outras providências.

Catanduva: Portal da Prefeitura de Catanduva. 
Correia, B. C. (2012). Esclarecimentos Sobre o Projeto Novo Recife - 2012. Recife: Direitos Urbanos. Recuperado em 30 de julho de 2020 de https://direitosurbanos.wordpress.com/2012/12/29/esclarecimentos-sobre-o-projeto-novo-recifepor-belize-camara/.

Cotia (2014). Lei Complementar n. 7908, de 2014. Dispõe sobre a revisão do Plano Diretor do Município de Cotia, instituído pela Lei Complementar n. 72, de 02 de janeiro de 2007 e dá outras providências. Cotia: Portal da Prefeitura de Cotia.

Cubatão (1999, 10 de setembro). Lei Complementar n. 2512, de 10 de setembro de 1999. Institui o novo Plano Diretor do município de Cubatão, e dá outra providências. Cubatã: Portal da Prefeitura de Cubatão.

Embu das Artes (2012, 20 de abril). Lei Complementar n. 186, de 20 de abril de 2012. Consolida as disposições do Plano Diretor do Município incorporando as revisões realizadas conforme determinação prevista no 3o artigo do 40 da Lei 10.257/01 e dá outras providências. Embu das Artes: Portal da Prefeitura de Embu das artes.

Ferraz de Vasconcelos (2006, 18 de outubro). Lei Complementar n. 175, de 18 de outubro de 2006. Dispõe sobre o Plano Diretor de Ferraz de Vasconcelos. Ferraz de Vasconcelos: Portal da Prefeitura de Ferraz de Vasoncelos.

Franca (2003, 17 de janeiro). Lei Complementar n.50, de 17 de janeiro de 2003. Institui o Plano Diretor do Município de Franca e dá outras providências. Franca: Portal da Prefeitura de Franca.

Francisco Morato (2006, 23 de novembro). Lei Complementar n.160, de 23 de novembro de 2006. Institui o Plano Diretor Participativo do município de Franciso Morato. Francisco Morato: Portal da Prefeitura de Fransciso Morato.

Fundação Sistema Educacional de Análise de Dados - SEADE. (2020). Perfil dos municípios paulistas. São Paulo: SEADE. Recuperado em 13 de fevereiro de 2020, de www.seade.gov.br

Franco da Rocha (2015, 03 de julho). Lei Complementar n. 244/2015. Alteração do Plano Diretor Participativo - Lei n. 618/2007 e dá outras providências. Franco da Rocha: Portal da Prefeitura de Franco da Rocha.

Guaratinguetá (2006, 23 de junho). Lei Complementar n. 23/06, de 23 de junho de 2006. Institui o novo Plano Diretor do Município de Guaratinguetá, nos termos do artigo 182 da Constituição Federal; do Capítulo III da Lei Federal n. 10.257, de 10 de julho de 2001 - Estatuto da Cidade. Guaratinguetá. Portal da Prefeitura de Guaratinguetá.

Guarujá (2013, 17 de dezembro). Lei Complementar n. 156/2013. Institui o Plano Diretor do Município de Guarujá e dá outras providências. Guarujá: Portal da Prefeitura de Guarujá.

Hortolândia (2008, 04 de julho). Lei n. 2.092, de 04 de julho de 2008. Dispõe sobre o Plano Diretor do Município de Hortolândia. Hortolândia: Portal da Prefeitura de Hortolândia.

Indaiatuba (2010, 22 de outubro). Lei Complementar n. 09, de 22 de outubro de 2010. Dispõe sobre a revisão e consolidação da Lei no 4.067 de 24 de setembro de 2001, que dispõe sobre a instituição do Plano Diretor do Município de Indaiatuba - PDI e dá outras providências. Indaiatuba: Portal da Prefeitura de Indaiatuba.

Itapecirica da Serra (2006, 26 de dezembro). Lei n. 1.771, de 26 de dezembro de 2006. Dispõe sobre a revisão do Plano Diretor Estratégico do Município de Itapecirica da Serra, instituído pela Lei Municipal n. 1.238, de 29 de maio de 2001. Itapecirica da Serra: Portal da Prefeitura de Itapecirica da Serra.

Itapetininga (2015). Lei Complementar n. 03/2015, de 2015. Dispõe sobre a revisão e a atualização do Plano Diretor do Município de Itapetininga e dá outras providências. Itapetininga: Portal da Prefeitura de Itapetininga.

Itapevi (2008, 26 de fevereiro). Lei Complementar n. 44, de 26 de fevereiro de 2008. Institui o Plano Diretor Participativo do Município e Itapevi. Itapevi: Portal da Prefeitura de Itapevi.

Itaquaquecetuba (2006, 01 de novembro). Lei Complementar n. 131, de 01 de novembro de 2006. Institui o Plano Diretor Estratégico de Itaquaquecetuba. Itaquaquecetuba: Portal da Prefeitura de Itaquaquecetuba.

Itatiba (2011, 20 de janeiro). Lei n. 4.325, de 20 de janeiro de 2011. Dispõe sobre o Plano Diretor do Município de Itatiba, que ordena o território e as políticas setoriais, e dá outras providências. Itatiba. Portal da Prefeitura de Itatiba.

Itu (2006, 10 e outubro). Lei Complementar n. 770, de 10 de outubro de 2006. Plano Diretor Participativo da Estância Turística de Itu. Itu: Portal da Prefeitura de Itu.

Jacareí (2003). Lei Complementar n. 49/2003. Plano Diretor de ordenamento territorial do Município de Jacareí. Jacareí: Portal da Prefeitura de Jacareí. 
Jandira (2006, 31 de outubro). Lei n. 1.603, de 31 de outubro de 2006. Institui o Plano Diretor do Município de Jandira. Jandira: Portal da Prefeitura de Jandira.

Jaú (2010, 29 de dezembro). Lei Complementar n. 389, de 29 de dezembro de 2010. Altera a Lei Complementar n. 277, de 10 de outubro de 2006, e dá outras providências. Jaí: Portal da Prefeitura de Jaú.

Lima, S. M. S. A., Lopes, W. G. R., \& Façanha, A. C. (2019). Desafios do planejamento urbano na expansão das cidades: entre planos e realidade. urbe. Revista Brasileira de Gestão Urbana, 11, e20180037. doi: https://dx.doi.org/10.1590/2175-3369.011.e20180037

Leme (1994,12 de dezembro). Lei Complementar n. 134, de 12 de dezembro de 1994. Dispõe sobre a instituição do Plano Diretor do município de Leme e dá outras providências. Leme: Portal da Prefeitura de Leme.

Lollo, J. A., Rohm, S. A. (2005). Aspectos negligenciados em estudos de impacto de vizinhança. Estudos Geográficos, 3(2), 31-45. Recuperado em 20 de setembro de 2020 de http://www.periodicos.rc.biblioteca.unesp.br/index.php/estgeo/article/view/239.

Marília (2006, 09 de outubro). Lei Complementar n. 480, de 09 de outubro de 2006. Plano Diretor do Município de Marília. Marília: Portal da Prefeitura de Marília.

Mogi Guaçu (2015, 26 de outubro). Lei Complementar n. 129, de 26 e outubro de 2015. Dispõe sobre a revisão do Plano Diretor de Desenvolvimento Integrado (PDDI) de Mogi Guaçu e dá outras providências. Mogi Guaçi: Portal da Prefeitura de Mogi Guaçu.

Ourinhos (2018, 03 de julho). Lei Complementar n. 990, de 03 de julho de 2018. Dispõe sobre a Revisão Decenal do Plano Diretor de Ourinhos e dá outras providências. Ourinhos: Portal da Prefeitura de Ourinhos.

Peres, R. B., \& Cassiano, A. (2019). O Estudo de Impacto de Vizinhança (EIV) nas regiões Sul e Sudeste do Brasil: avanços e desafios à gestão ambiental urbana. urbe. Revista Brasileira de Gestão Urbana, 11, 1-15. doi: 101590/21753369.011.e20180128.

Peres, R. B., \& Cassiano, A. M. (2017). Inter-relações entre o Estudo de Impacto de Vizinhança (EIV) e o Estudo de Impacto Ambiental (EIA): perspectivas e contribuições às políticas públicas ambientais urbanas. In Anais do XVII Encontro Nacional da Associação Nacional de Pós-Graduação e Pesquisa em Planejamento Urbano e Regional. (p. 1-20). São Paulo: ANPUR.

Pindamonhangaba (2006, 10 de outubro). Lei Complementar n.3. de 10 de outubro de 2006. Institui o Plano Diretor Participativo de Pindamonhangaba. Pindamonhangaba: Portal da Prefeitura de Pindamonhangaba.

Piracicaba (2006, 10 de outubro). Lei Complementar 186, de 26 de outubro de 2006. Aprova o Plano Diretor de Desenvolvimento do município de Piracicaba, cria o conselho da cidade, revoga a Lei Complementar n. 46/95 e suas alterações e dá outras providências Piracicaba: Portal da Prefeitura de Piracicaba.

Poá (2006, 05 de dezembro). Lei n. 3.201 de dezembro de 2006. Institui o Plano Diretor de Desenvolvimento integrado da Estância Hidromineral de Poá e dá outras providências. Poá: Portal da Prefeitura de Poá.

Praia Grande (2016, 16 de dezembro). Lei Complementar n. 727, de 16 de dezembro de 2016. Aprova a revisão do Plano Diretor da Estância Balneária de Praia Grande para o período d 2017 a 2026. Praia Grande: Portal da Prefeitura de Praia Grande.

Presidente Prudente (2018). Lei Complementar n. 230/2018. Dispõe sobre a Lei do Plano Diretor do Município e dá outras providências. Presidente Prudente: Portal da Prefeitura de Presidente Prudente.

Ribeirão Pires (2014, 23 de outubro). Lei n. 5907, de 23 de outubro de 20014. Efetua a revisão da Lei n. 4,791, de 14 de setembro de 2004 - Plano Diretor do Município da Estância Turística de Ribeirão Pires, nos termos do artigo 40 da Lei Federal no 10.257, de 10 de julho de 2001, e dá outras providências. Ribeirão Pires: Portal da Prefeitura de Ribeirão Pires.

Rio Claro (2017, 04 de dezembro). Lei Complementar n. 0128 de 04 de dezembro de 2017. Institui o Plano Diretor de Desenvolvimento do Município de Rio Claro. Rio Claro: Portal da Prefeitura de Rio Claro.

Rolnik, R. (2015). Guerra dos lugares: a colonização da terra e da moradia na era das finanças. São Paulo: Boitempo.

Salto (2006). Lei n. 2.771, de 2006. Institui o Plano Diretor da Estância Turística de Salto e dá outras providências. Salto: Portal da Prefeitura de Salto. 
Santa Barbara D’Oeste (2017, 14 de dezembro). Lei Complementar n. 265, de 14 de dezembro de 2017. Institui o Plano Diretor de Desenvolvimento do Município de Santa Barbara d'Oeste e dá outras providências. Santa Barbara d'Oeste: Portal da Prefeitura de Santa Bárbara d'Oeste.

Santana de Parnaíba (2006, 17 de novembro). Lei Complementar n. 30, de 17 de novembro de 2006. Dispõe sobre o Plano Diretor de Santana de Parnaíba, para o período 2006/2013, e dá outras providências. Santana de Parnaíba: Portal da Prefeitura de Santana de Parnaíba.

São Caetano do Sul (2015, 09 de dezembro). Lei n. 5.374, de 09 de dezembro da 2015. Institui o Plano Diretor Estratégico de São Caetano do Sul - 2016/2025, e dá outras providências. São Caetano do Sul: Portal da Prefeitura de São Caetano do Sul.

São Carlos (2018, dezembro). Lei n. 18.053, de dezembro de 2018. Institui o Plano Diretor de São Carlos. São Carlos: Portal da Prefeitura de São Carlos.

São Vicente (1999). Lei Complementar n.270/1999, de 1999. Institui o Plano Diretor Municipal de São Vicente. São Vicente: Portal da Prefeitura de São Vicente.

Sertãozinho (2008). Lei Complementar n. 201/2008, de 2008. Cria o Plano Diretor do Município e da outras providências. Sertãozinho: Portal da Prefeitura de Sertãozinho.

Schvarsberg, B., Martins, G. C., Kallas, L., Cavalcanti, C. B., \& Teixeira, L. M. (Orgs.) (2016). Estudo de Impacto de Vizinhança: Caderno Técnico de Regulamentação e Implementação. Secretaria Nacional de Acessibilidade e Programas Urbanos, Programa Nacional de Capacitação das Cidades e Universidade de Brasília. Brasília: Universidade de Brasília.

Silva, P. D. D. S., \& Lollo, J. A. (2013). O estudo de impacto de vizinhança como instrumento para o desenvolvimento da qualidade de vida urbana. HOLOS Environment, 13(2), 151-162. doi.org/10.14295/holos.v13i2.6361.

Sumaré (2006, 06 de outubro). Lei n. 4250, de 06 de outubro de 2006. Dispõe sobre o Plano Diretor. Sumaré: Portal da Prefeitura de Sumaré.

Suzano (2017, 22 de dezembro). Lei Complementar n. 312, de 22 de dezembro de 2017. Institui o Plano Diretor do Município de Suzano, e dá outras providências. Suzano: Portal da Prefeitura de Suzano.

Taboão da Serra (2006, 26 de dezembro). Lei Complementar n. 132, de 26 de dezembro de 2006. Institui sobre o Plano Diretor Participativo e o sistema de planejamento integrado e gestão participativa do município de Taboão da Serra, nos termos dos artigos 182 e 183 da Constituição Federal, do Capítulo III da lei 10.257, de 10 de julho de 2001 Estatuto da Cidade -e da lei orgânica do município de Taboão da Serra. Taboão da Serra: Portal da Prefeitura de Taboão da Serra.

Tatuí (2006, 16 de dezembro). Lei Municipal n. 3.885, de 18 de outubro de 2006. Institui o Plano Diretor de Tatuí. Tatuí: Portal da Prefeitura de Tatuí.

Taubaté (2017, 12 de julho). Lei Complementar n. 412, de 12 de julho de 2017. Institui o Plano Diretor Físico do Município de Taubaté e dá outras providências. Taubaté: Portal da Prefeitura de Taubaté.

Vainer, C., Otilia, A., Maricato, C. (2000). A Cidade do Pensamento Único: Desmanchando Consensos (1a ed., Vol. 1). Petrópolis: Vozes.

Várzea Paulista (2006, 09 de outubro). Lei Complementar n. 167, de 09 de outubro de 2006. Institui o Plano Diretor de Várzea Paulista e dá outras providências. Várzea Paulista: Portal da Prefeitura de Várzea Paulista.

Villaça, F. (2001). Espaço intra-urbano no Brasil (2a ed., Vol. 1). São Paulo: Studio Nobel.

Votorantim (2015, 17 de dezembro). Lei Complementar n.4, de 17 de dezembro de 2015. Dispõe sobre o Plano Diretor de Desenvolvimento Integrado do Município de Votorantim e dá outras providências. Votorantim: Portal da Prefeitura de Votorantim.

Editor responsável: Fábio Duarte

Recebido em 11 mai. 2020

Aprovado em 04 out. 2020 